\title{
Subacute administration of crude khat (Catha edulis F.) extract induces mild to moderate nephrotoxicity in rats
}

\author{
Zewdneh Shewamene and Ephrem Engidawork
}

\begin{abstract}
Background: Although various studies have been conducted to shed light on the pharmacological actions of khat, little or no data are available regarding khat's effect on the renal redox system. The aim of this study was therefore to investigate the potential of nephrotoxicity associated with khat exposure in rats.

Methods: Sprague Dawely rats were randomly assigned into eight experimental groups. Animals were treated with Tween80, gentamicin $100 \mathrm{mg} / \mathrm{kg}$ and khat at various doses (100, 200 and $400 \mathrm{mg} / \mathrm{kg}$ ) alone or in combination with gentamicin for ten days. The animals were then sacrificed to obtain blood and renal tissues for subsequent analysis. Renal markers, including creatinine, blood urea nitrogen, antioxidant enzymes as well as markers for lipid peroxidation were determined using established protocols. In addition, histopathological changes were evaluated with hematoxilin and-eosin staining technique.

Results: Lower and moderate doses of khat did not alter the measured parameters compared to controls. By contrast, higher dose $(400 \mathrm{mg} / \mathrm{kg})$ of khat not only increased levels of serum creatinine and blood urea nitrogen $(p<0.001)$ but also levels of malondialdehyde $(p<0.01)$. Moreover, $400 \mathrm{mg} / \mathrm{kg}$ of khat significantly decreased enzymatic activities of superoxide dismutase $(p<0.01)$ and catalase $(p<0.001)$. When khat was administered with gentamicin, it was again the higher dose that significantly accentuated gentamicin-induced alterations in the renal system.
\end{abstract}

Conclusions: Khat treatment at high dose is demonstrated to induce mild to moderate renal damage. Moreover, it creates synergy when combined with nephrotoxic drugs such as gentamicin.

Keywords: Nephrotoxicity, Superoxide dismutase, Catalase, Malondialdehyde, Khat, Rat

\section{Background}

Khat (Catha edulis Forsk) is a shrub or small to mediumsized evergreen tree that belongs to the Celastraceae family. It is cultivated mainly in Yemen and East African Countries [1]. The shrub grows to a height of 6 meters and the leaves are leathery, glossy, brownish green, with serrated edges, arranged in an alternate fashion on straight branches. The young shoots and leaves are parts that are chewed for their psychoactive properties [2].

In Ethiopia, a number of local brands are available, including Aweday, Beleche, Abo mismar, Gelemso and Wondo. It is claimed that the Aweday variety cultivated

\footnotetext{
* Correspondence: ephrem.engidawork@aau.edu.et

Department of Pharmacology and Clinical Pharmacy, School of Pharmacy, Addis Ababa University, P.O, Box 1176, Addis Ababa, Ethiopia
}

in Harar highlands of Eastern Ethiopia is the most potent and expensive among the local brands, and hence chosen for export $[3,4]$ as well as for purpose of the present study. Central nervous system stimulation such as euphoria and alertness induced by cathinone, the main active constituent derived from khat chewing, makes it popular among large segments of the society. In addition, factors like easy transportation from village to city khat markets and affordability are thought to play an important role in widening its social use in society. People also believe that khat helps to work more effectively, particularly with manual work, due to increased energy and alertness [5].

Consumption of crude khat extract or its alkaloid fraction preceding stress has been shown to produce oxidative 
stress in rats by altering activities of serum antioxidant enzymes [6]. Nephrotoxic and hepatotoxic effects are also reported following khat administration to New Zealand white rabbits $[7,8]$. The generation of free radicals is seriously implicated in khat toxicity following the observation that oral exposure of rats to khat was associated with decreased serum free radicals metabolizing enzymes such as superoxide dismutase (SOD) and catalase [9]. In addition, khat treated rats displayed hepatic enlargement, abnormal findings in serum aspartate aminotransferase, and alkaline phosphatase in both sexes as well as alterations in serum albumin and creatinine in female rats [10].

In spite of the vast published data on the pharmacology and chemistry of khat, toxicological studies with laboratory animals as well as toxicity reports in humans, particularly on the renal system, are scanty. Moreover, the effect of khat-induced redox changes, at least, in the kidney, has not yet been explored. Thus, there is a need for conducting laboratory studies to generate a sufficient body of knowledge in the area. This study therefore attempted to investigate whether exposure of rats to khat had a potential to cause nephrotoxicity via alteration of the renal redox system.

\section{Methods}

\section{Collection of plant material}

Bundles of fresh khat shoots and small branches were purchased $(2000 \mathrm{~g})$ fresh at a local market, Aweday, located $525 \mathrm{~km}$ South East of Addis Ababa, Ethiopia. The fresh bundles were packed in plastic bags and transported in an icebox to the laboratory. The plant was identified by a taxonomist and a voucher specimen (ZS001) was deposited at the National Herbarium, College of Natural Sciences, Addis Ababa University for future reference. The fresh leaves were immediately kept at $-20^{\circ} \mathrm{C}$ for two days before subjected to extraction.

\section{Experimental animals}

Sixty four (32 male and 32 female) healthy Sprague Dawley rats (6-8 weeks of age and $170-210 \mathrm{~g})$ bred in the animal house of School of Pharmacy, Addis Ababa University were used for the experiment. The rats were housed in polypropylene cages and maintained under room temperature $\left(22-25^{\circ} \mathrm{C}\right)$, relative humidity of $50 \%$ and $12 \mathrm{~h}$ light/dark cycle. Animals were provided with pelletized feed and tap water ad libitum. All animals were handled according to internationally accepted guidelines [11] and the protocol was approved by the School of Pharmacy Ethics Committee.

\section{Extraction of khat}

Extraction was performed as described elsewhere with slight modification $[12,13]$. The freeze-dried plant was finely minced, weighed and placed in Erlenmeyer flasks
(400 g per flask) wrapped with aluminum foil to avoid light induced decomposition. Chloroform $(150 \mathrm{~mL})$ and diethyl ether $(450 \mathrm{~mL})(1: 3 \mathrm{v} / \mathrm{v})$ were added to cover the minced leaves. The resulting mixture was shaken under dark condition for $24 \mathrm{~h}$ using a rotary shaker (New Brunswick Scientific Co, USA) at $120 \mathrm{rpm}$ and $20^{\circ} \mathrm{C}$.

The mixture was later filtered through a folded filter paper. The filtrate was again passed through a round filter paper with the help of a mini filter pump. The organic filtrate collected in this way was pooled together in a wide mouth amber bottle and placed in a hood for $24 \mathrm{~h}$ to remove the organic solvents. The residue was left overnight in a deep freezer and then lyophilized using a freeze dryer (Christ 100400, Bioblock Scientific, France). The yield was calculated and found to be $1.02 \%$, which was similar with previous works [14-16].

\section{Grouping and dosing of animals}

Animals were randomly assigned into 8 experimental groups, consisting of 8 (four male and four female) animals per group. The first group served as control (CON) and given the vehicle used for reconstitution of the extract (Tween $80,2 \% \mathrm{v} / \mathrm{v}$ in water). The second, third and fourth groups received crude khat extract at doses of $100 \mathrm{mg} / \mathrm{kg}$ (K100), $200 \mathrm{mg} / \mathrm{kg}$ (K200) and $400 \mathrm{mg} / \mathrm{kg}$ (K400) for ten days. The fifth group (GEN) was treated with gentamicin for eight days at a dose of $100 \mathrm{mg} / \mathrm{kg}$ [17]. The rest of the groups received crude khat extract at doses of $100 \mathrm{mg} / \mathrm{kg}$ (GK100), $200 \mathrm{mg} / \mathrm{kg}$ (GK200) and $400 \mathrm{mg} / \mathrm{kg}$ (GK400) for two days before and eight days concomitantly with gentamicin $(100 \mathrm{mg} / \mathrm{kg})$. Vehicle and extracts were administered via the oral route, while gentamicin was administered intraperitoneally. Rats were weighed on alternate days and the last known weight was used for dose calculation. The dose for the khat extract was selected based on previous reports $[13,14,16]$.

\section{Sample collection}

Twenty-four hours after the last treatment, animals were slightly anesthetized with ether inhalation and bilateral prilumbal vertical incisions were made to draw blood via cardiac puncture. The blood samples were left at room temperature for $30 \mathrm{~min}$ to coagulate. Serum was then separated by centrifuging the samples for $15 \mathrm{~min}$ at $3000 \mathrm{rpm}$ and $4^{\circ} \mathrm{C}$ (Centurion Scientific Ltd K240R, UK). The serum was stored at $-20^{\circ} \mathrm{C}$ for $48 \mathrm{~h}$ until subjected to analysis for determination of creatinine and blood urea nitrogen (BUN) levels. In parallel, both kidneys were removed and used for enzyme assay and histopathological studies. The right kidney was rinsed with chilled saline, decapsulated, blotted on a filter paper and quickly weighed. It was then homogenized in ice-cold saline to produce a $10 \%$ $(\mathrm{w} / \mathrm{v})$ tissue homogenate and stored at $-20^{\circ} \mathrm{C}$ until assayed for the redox markers. 


\section{Biochemical analysis}

\section{Serum creatinine and BUN measurement}

The concentration of serum creatinine and BUN were measured by Cobas integra 400 (Roche, Switzerland) using commercial kits (Roche-Cobas, Switzerland) according to the manufacturer's protocol. Creatinine level was determined by Jaffe's reaction without deproteinization, where the samples were subjected to react with picrate in alkaline $\mathrm{pH}$ forming a yellow-red color with maximum absorbance at $512 \mathrm{~nm}$. For measurement of BUN level, kinetic test with urease and glutamate dehydrogenase was used. Urea in the sample was hydrolyzed by urease forming ammonia that in turn reacts with 2-oxoglutarate in the presence of glutamate dehydrogenase and reduced nicotinamide adenine dinucleotide (NADH) to produce L-glutamate. The rate of decrease in the NADH concentration is directly proportional to the urea in the sample and this can be determined by measuring the absorbance at $340 \mathrm{~nm}$. The BUN was calculated from urea using a formula BUN $(\mathrm{mg} / \mathrm{dl})=$ urea $\times 0.467$.

\section{Determination of total superoxide dismutase activity}

The total SOD activity was determined using commercial kits (Nanjing NianChen Bioengineering Institute, China). The reaction system consisted of xanthine and xanthine oxidase that produces superoxide radical $\left(\mathrm{O}_{2}^{-}\right)$. The $\mathrm{O}_{2}^{-}$ oxidizes hydroxylamine forming nitrite, which colors amaranth by the color developer and this can be assayed at $550 \mathrm{~nm}$ (Unic model 2100 spectrophotometer). During the assay, $50 \mu \mathrm{l}$ of $10 \%$ tissue homogenates were mixed well with the reaction system on a vortex mixer (Labnet S0100-230 V, Labnet International Inc., USA) and incubated in a water bath maintained at $37^{\circ} \mathrm{C}$ (Oakton Stable Temp WD-1250-15, USA) for $40 \mathrm{~min}$. The formation of $\mathrm{O}_{2}^{-}$and nitrite was inhibited by SOD in the samples, reducing the intensity of the amaranth color as well as the absorbance upon addition of the color developing agent. The total SOD activity in the sample was calculated and expressed as U/mg protein. One unit of SOD activity is defined as the amount of SOD that will produce $50 \%$ inhibition of oxidation of hydroxylamine induced by xanthine and xanthine oxidase at $37^{\circ} \mathrm{C}$ in $1 \mathrm{mg} / \mathrm{ml}$ protein concentration of tissue homogenate.

\section{Determination of catalase activity}

Catalase activity was measured based on the manufacturer's protocol (Nanjing NianChen Bioengineering Institute, China) that relies on the reaction of enzyme in the presence of an optimal concentration of $\mathrm{H}_{2} \mathrm{O}_{2}$. The rate of dismutation of $\mathrm{H}_{2} \mathrm{O}_{2}$ to $\mathrm{H}_{2} \mathrm{O}$ and $\mathrm{O}_{2}$ is proportional to the concentration of catalase. Briefly, $50 \mu \mathrm{l}$ of $10 \%$ renal tissue homogenates were mixed well with a known concentration of $\mathrm{H}_{2} \mathrm{O}_{2}$ on a vortex mixer and incubated in a water bath at $37^{\circ} \mathrm{C}$ for $1 \mathrm{~min}$. Ammonium molybdate was added to the mixture to quench the reaction and react with the remained $\mathrm{H}_{2} \mathrm{O}_{2}$, forming a stable colored complex. The absorbance of the complex was measured at $405 \mathrm{~nm}$. Finally, the catalase catalytic activity of the tissue samples was calculated and expressed as $\mathrm{U} / \mathrm{mg}$ protein. One unit of catalase catalytic activity is defined as the amount of enzyme that will decompose $1 \mu \mathrm{mol} \mathrm{H}_{2} \mathrm{O}_{2}$ per second at $37^{\circ} \mathrm{C}$ in $1 \mathrm{mg}$ protein of tissue homogenate.

\section{Determination of malondialdehyde level}

The amount of lipid peroxides was calculated as thiobarbituric acid reacting substances such as malondialdehyde (MDA) formed from the breakdown of polyunsaturated fatty acids, which is considered as an index for the peroxidation reaction. The level of MDA in renal homogenate was assayed using commercial kits (Nanjing NianChen Bioengineering Institute, China) based on thiobarbituric acid method, where MDA undergoes condensation reaction with thiobarbituric acid, generating a red product that has a maximum absorption peak at $532 \mathrm{~nm}$. Briefly, tissue homogenates $(10 \%)$ were well mixed with thiobarbituric acid reaction system in test tubes on a vortex mixer. The test tubes were then sealed with aluminum foil with a hole stung with a needle. The mixture was incubated at $95^{\circ} \mathrm{C}$ in a water bath for $40 \mathrm{~min}$, cooled with flowing water and then centrifuged at $4000 \mathrm{rpm}$ for $10 \mathrm{~min}$. The supernatant was carefully pippeted into quartz cuvete (Exactaoptech, Germany) to read the absorbance of the red color at $532 \mathrm{~nm}$ and MDA level was determined.

\section{Morphometric analysis Body and kidney weight changes}

Body weight of all animals before and after the experiment was taken and the difference was expressed as body weight change. The final day body weight was used for the calculation of body weight change and expression of normalized kidney weight [18]. The weight of both right and left kidneys of each rat was measured at the end of treatment after sacrificing the animal. For standardization, total weight of both kidneys/100 g body weights was determined [19].

\section{Histopathological examination}

The left kidney tissues fixed in $10 \%$ formalin were dehydrated with absolute ethanol solution, cleaned in xylene and embedded in paraffin. The prepared tissue was then sectioned at $5 \mu \mathrm{m}$ and stained with hematoxylin and eosin for microscopical examination. Coded slides were examined by a blinded pathologist for histopathological changes such as tubular necrosis, inflammation, hyaline casts, and hydropic degeneration. 


\section{Statistical analysis}

All data are presented as mean \pm standard error of the mean and SPSS data analysis software version 19 was used for data processing. The analysis was performed by one way ANOVA followed by Tukey's multiple comparison tests. Level of significance was set at $\mathrm{p}<0.05$.

\section{Results}

Serum creatinine and blood urea nitrogen levels

Table 1 shows the change in serum markers of all experimental groups. K100 and K200 did not produce detectable changes in the serum markers. Administration of $\mathrm{K} 400$, on the other hand, significantly increased creatinine $(54.2 \%, \mathrm{p}<0.001)$ as well as BUN $(30.2 \%, \mathrm{p}<0.001)$ levels compared to CON rats. Moreover, K400 rats had a significantly greater levels of the markers compared to K100 ( $\mathrm{p}<0.001)$ as well as K200 ( $<<0.01$ for creatinine and $\mathrm{p}<0.05$ for BUN) rats. It is of note that levels of both markers were significantly elevated $(\mathrm{p}<0.001)$ in GEN rats compared to all other groups.

In parallel experiment, khat was administered concomitantly with gentamicin to see whether khat synergizes the toxic effect of gentamicin. The results indicated that whilst no apparent changes were observed with GK100 and GK200, GK400 demonstrated a significantly elevated creatinine $(25 \%, \mathrm{p}<0.001)$ and BUN $(19.9 \%, \mathrm{p}<0.001)$ levels compared to GEN rats (Table 2).

\section{Effects on antioxidant enzymes and lipid peroxidation} K400 rats exhibited a significant decrease in SOD (14.8\%, $\mathrm{p}<0.01)$ and catalase $(35 \%, \mathrm{p}<0.001)$ activities compared to $\mathrm{CON}$ rats. Significantly greater reduction in the activity of both enzymes ( $\mathrm{p}<0.001$ in both cases) was also noted in GEN compared to $\mathrm{CON}$ as well as khat-treated rats (Table 3). MDA levels were markedly increased by K200 (41.5\%, p<0.05), K400 (103.8\%, p<0.01) and GEN $(141.2 \%, \mathrm{p}<0.001)$ compared to CON rats. The increase observed in MDA levels by GEN once again was significantly higher than K100 (119.2\%, p < 0.001), K200 (70.3\%, $\mathrm{p}<0.001)$ and $\mathrm{K} 400(18.3 \%, \mathrm{p}<0.01)$ rats (Table 3$)$.

Table 1 Effects of khat extract on serum creatinine and blood urea nitrogen levels

\begin{tabular}{lcc}
\hline Groups & Serum creatinine $(\mathbf{m g} / \mathbf{d l})$ & Blood urea nitrogen $(\mathbf{m g} / \mathbf{d l})$ \\
\hline CON & $0.59 \pm 0.02$ & $19.92 \pm 0.34$ \\
K100 & $0.63 \pm 0.02$ & $20.15 \pm 0.42$ \\
K200 & $0.66 \pm 0.05$ & $20.79 \pm 0.40$ \\
K400 & $0.91 \pm 0.02^{\mathrm{a} 3 \mathrm{~b} 3 c 2}$ & $25.94 \pm 0.53^{\mathrm{a3b3c1}}$ \\
GEN & $1.24 \pm 0.03^{\mathrm{a3b} 3 c 3 \mathrm{~d} 3}$ & $48.25 \pm 0.97^{\mathrm{a} 3 \mathrm{~b} 3 \mathrm{c} 3 \mathrm{~d} 3}$
\end{tabular}

Values are mean \pm SEM. $\mathrm{n}=8$; ${ }^{\mathrm{a}}$ compared to $\mathrm{CON} ;{ }^{\mathrm{b}}$ compared to $\mathrm{K} 100$; compared to K200; ${ }^{\mathrm{d}}$ Compared to K400. ${ }^{1} \mathrm{p}<0.05 ;{ }^{2} \mathrm{p}<0.01 ;{ }^{3} \mathrm{p}<0.001$. (CON: control, received Tween80; K100, khat 100 mg/kg; K200, khat 200 mg/ kg; K400, khat 400 mg/kg; GEN, gentamicin 100 mg/kg).
Table 2 Effects of khat and gentamicin co-administration on serum creatinine and blood urea nitrogen levels

\begin{tabular}{ccc}
\hline Groups & Serum creatinine $(\mathbf{m g} / \mathbf{d l})$ & Blood urea nitrogen $(\mathbf{m g} / \mathbf{d l})$ \\
\hline GEN & $1.24 \pm 0.03$ & $48.25 \pm 0.97$ \\
GK100 & $1.28 \pm 0.03$ & $49.42 \pm 1.02$ \\
GK200 & $1.30 \pm 0.02$ & $49.94 \pm 0.71$ \\
GK400 & $1.55 \pm 0.06^{\mathrm{a} 3}$ & $57.83 \pm 0.79$ а3 \\
\hline
\end{tabular}

Values are mean \pm SEM. $n=8$; ${ }^{a}$ compared to GEN. ${ }^{1} p<0.05 ;{ }^{2} p<0.01$; ${ }^{3} \mathrm{p}<0.001$. (GEN: gentamicin $100 \mathrm{mg} / \mathrm{kg}$; GK100: gentamicin $100 \mathrm{mg} / \mathrm{kg}+$ Khat 100 mg/kg; GK200: gentamicin 100 mg/kg + Khat 200 mg/kg; GK400: gentamicin $100 \mathrm{mg} / \mathrm{kg}$ + Khat $400 \mathrm{mg} / \mathrm{kg}$ ).

Table 4 illustrates the effect of crude khat extract when given concomitantly with gentamicin on renal redox markers. Compared to GEN rats, GK100 and GK200 tended to have a reduced renal activity of SOD and catalase that failed to reach statistical significance. By contrast, GK400 group revealed a significant reduction in activity of both SOD $(25.7 \%, \mathrm{p}<0.05)$ and catalase $(49.4 \%, \mathrm{p}<0.01)$. Whilst no apparent difference was observed with the other doses, khat at a dose of $400 \mathrm{mg} / \mathrm{kg}$ along with gentamicin displayed a significant increase $(38.6 \%, \mathrm{p}<0.001)$ in MDA levels when compared with gentamicin alone.

\section{Effects on body weight change and normalized kidney weight}

At the end of the experiment, percent body weight change was determined for each group of animals (Tables 5 and 6). It was found out that whereas no appreciable change was observed in body weight change with K100; significant body weight loss was detected with K200 (p < 0.05), K400 $(\mathrm{p}<0.01)$ and GEN $(\mathrm{p}<0.001)$ rats compared to CON. Moreover, body weight loss following gentamicin treatment was significantly greater $(\mathrm{p}<0.001)$ compared to all groups of khat treated rats.

Rats treated with K100 and K200 showed slight kidney weight gain without statistical significance as compared to CON rats (Table 5). Treatment with crude khat extract at a dose of $400 \mathrm{mg} / \mathrm{kg}$ produced a significant $(\mathrm{p}<0.05)$

Table 3 Effects of khat extract on activity of renal antioxidant enzymes and levels of malondialdehyde in rats

\begin{tabular}{cccc}
\hline Groups & $\begin{array}{c}\text { SOD } \\
\text { (U/mg protein) }\end{array}$ & $\begin{array}{c}\text { CAT } \\
\text { (U/mg protein) })\end{array}$ & $\begin{array}{c}\text { MDA } \\
\text { (nmol/mg protein) }\end{array}$ \\
\hline CON & $259.50 \pm 7.56$ & $17.69 \pm 0.73$ & $2.60 \pm 0.04$ \\
K100 & $249.49 \pm 11.49$ & $17.62 \pm 0.56$ & $2.86 \pm 0.07$ \\
K200 & $240.66 \pm 6.97$ & $16.20 \pm 0.40$ & $3.68 \pm 0.17^{\mathrm{a} 1}$ \\
K400 & $221.17 \pm 7.51^{\mathrm{a} 2}$ & $11.50 \pm 0.87^{\mathrm{a} 3}$ & $5.30 \pm 0.16^{\mathrm{a} 2}$ \\
GEN & $136.43 \pm 4.94^{\mathrm{a} 3 \mathrm{~b} 3 \mathrm{c} 3 \mathrm{~d} 3}$ & $6.54 \pm 0.47^{\mathrm{a} 3 \mathrm{~b} 3 \mathrm{c} 3 \mathrm{~d} 3}$ & $6.27 \pm 0.19^{\mathrm{a} 3 \mathrm{~b} 3 \mathrm{c} 3 \mathrm{~d} 3}$ \\
\hline
\end{tabular}

Values are mean \pm SEM. $\mathrm{n}=8$; $^{\mathrm{a}}$ Compared to $\mathrm{CON} ;{ }^{\mathrm{b}}$ Compared to $\mathrm{K} 100$; c compared to K200; ${ }^{d}$ compared to K400. ${ }^{1} \mathrm{p}<0.05 ;{ }^{2} \mathrm{p}<0.01 ;{ }^{3} \mathrm{p}<0.001$. (CON: control, received Tween80; K100, khat 100 mg/kg; K200, khat 200 mg/kg; $\mathrm{K} 400$, khat $400 \mathrm{mg} / \mathrm{kg}$; GEN, gentamicin $100 \mathrm{mg} / \mathrm{kg}$; SOD, superoxide dismutase; CAT, catalase; MDA, malondialdehyde). 
Table 4 Effects of khat and gentamicin co-administration on activity of renal antioxidant enzymes and levels of malondialdehyde in rats

\begin{tabular}{cccc}
\hline Groups & $\begin{array}{c}\text { SOD } \\
\text { (U/mg protein) }\end{array}$ & $\begin{array}{c}\text { CAT } \\
\text { (U/mg protein) }\end{array}$ & $\begin{array}{c}\text { MDA } \\
\text { (nmol/mg protein) }\end{array}$ \\
\hline GEN & $136.43 \pm 4.94$ & $6.54 \pm 0.47$ & $6.273 \pm 0.1974$ \\
GK100 & $134.86 \pm 3.23$ & $5.72 \pm 0.27$ & $6.749 \pm 0.1981$ \\
GK200 & $126.08 \pm 8.23$ & $4.60 \pm 0.18$ & $6.935 \pm 0.2460$ \\
GK400 & $101.33 \pm 3.48^{\mathrm{a} 3}$ & $3.31 \pm 0.46^{\mathrm{a} 3}$ & $8.694 \pm 0.2184^{\mathrm{a} 3}$ \\
\hline
\end{tabular}

Values are mean \pm SEM. $n=8$; ${ }^{\text {a }}$ compared to GEN; ${ }^{3} \mathrm{p}<0.001$. (GEN: gentamicin 100 mg/kg; GK100: gentamicin 100 mg/kg + Khat 100 mg/kg; GK200: gentamicin $100 \mathrm{mg} / \mathrm{kg}$ + Khat 200 mg/kg; GK400: gentamicin $100 \mathrm{mg} / \mathrm{kg}$ + Khat 400 mg/kg; SOD, superoxide dismutase; CAT, catalase; MDA, malondialdehyde).

increase in normalized kidney weight compared to CON. GEN rats also revealed a significantly increased kidney weight gain $(\mathrm{p}<0.001)$ not only compared to CON but also with all khat groups. Significant body weight loss or kidney weight gain was not observed between K100, K200 and $\mathrm{K} 400$ rats.

As illustrated in Table 6, concomitant treatment of khat at a dose of $400 \mathrm{mg} / \mathrm{kg}$ with gentamicin induced a significantly greater $(\mathrm{p}<0.01)$ body weight loss as well as kidney weight gain $(\mathrm{p}<0.01)$ compared to gentamicin alone.

\section{Histopathological studies}

Histological changes in the kidneys are depicted in Figure 1. Kidneys of control group showed normal renal parenchyma with normal histoarchitecture (Figure 1A). K400 induced histopathological changes as evidenced by mild renal interstitial inflammation, hypertrophied glomerular capillaries and injured dilated Bowman's capsule (Figure 1B). Gentamicin induced changes were more extensive than khat groups (Figure 1C). Furthermore, GK400 rats revealed more extensive and marked infiltrative inflammation, complete destruction of glomerular capillaries, degeneration of the tubules and foamy appearance in the tubular epithelial cells (Figure 1D).

Table 5 Effects of khat extract on body weight change and normalized kidney weight

\begin{tabular}{lcc}
\hline Groups & $\begin{array}{c}\text { Body weight } \\
\text { change (\%) }\end{array}$ & $\begin{array}{c}\text { Kidney weight } \\
(\mathbf{g m}) / \mathbf{1 0 0} \text { g body weight }\end{array}$ \\
\hline CON & $2.83 \pm 0.48$ & $0.70 \pm 0.01$ \\
K100 & $2.22 \pm 0.69$ & $0.73 \pm 0.01$ \\
K200 & $0.32 \pm 0.46^{\mathrm{a} 1}$ & $0.74 \pm 0.01$ \\
K400 & $-4.96 \pm 0.28^{\mathrm{a} 2}$ & $0.82 \pm 0.01$ a1 \\
GEN & $-10.36 \pm 57^{\text {a3b3c3d3 }}$ & $0.89 \pm 0.01^{\mathrm{a3b3c3d} 3}$
\end{tabular}

Values are mean \pm SEM. $\mathrm{n}=8$; ${ }^{\mathrm{a}}$ compared to $\mathrm{CON},{ }^{\mathrm{b}}$ compared to $\mathrm{K} 100$, compared to K200, ${ }^{d}$ compared to K400. ${ }^{1} \mathrm{p}<0.05 ;{ }^{2} \mathrm{p}<0.01 ;{ }^{3} \mathrm{p}<0.001$. (CON: control; K100: khat 100 mg/kg; K200: khat 200 mg/kg; K400: khat $400 \mathrm{mg} / \mathrm{kg}$; GEN: gentamicin $100 \mathrm{mg} / \mathrm{kg}$ ).
Table 6 Effects of khat extract and gentamicin co-administration on body weight change and normalized kidney weight

\begin{tabular}{ccc}
\hline Groups & $\begin{array}{c}\text { Body weight } \\
\text { change }(\mathbf{g m})\end{array}$ & $\begin{array}{c}\text { Kidney weight } \\
(\mathbf{g m}) / \mathbf{1 0 0} \text { g body weight }\end{array}$ \\
\hline GEN & $-10.36 \pm 0.57$ & $0.89 \pm 0.01$ \\
GK100 & $-10.85 \pm 0.86$ & $0.89 \pm 0.02$ \\
GK200 & $-11.75 \pm 0.84$ & $0.90 \pm 0.01$ \\
GK400 & $-15.13 \pm 1.37^{\text {a3 }}$ & $1.00 \pm 0.02{ }^{\text {a2 }}$ \\
\hline
\end{tabular}

Values are mean \pm SEM. $n=8$; ${ }^{a}$ compared to GEN. ${ }^{1} p<0.05 ;{ }^{2} p<0.01$;

${ }^{3} \mathrm{p}<0.001$. (GEN: gentamicin $100 \mathrm{mg} / \mathrm{kg}$; GK100: gentamicin $100 \mathrm{mg} / \mathrm{kg}+$ Khat 100 mg/kg; GK200: gentamicin 100 mg/kg + Khat 200 mg/kg; GK400: gentamicin $100 \mathrm{mg} / \mathrm{kg}$ + Khat $400 \mathrm{mg} / \mathrm{kg}$ ).

\section{Discussion}

In this study, the effect of khat administration alone or with gentamicin was studied in terms of alteration of renal markers, including creatinine, BUN, antioxidant enzymes as well as markers for lipid peroxidation. In addition, histopathological changes such as presence of inflammation, tubular degeneration, hyaline casts and vascular congestions were evaluated. Gentamicin-induced nephrotoxicity in rodents is a well documented model for acute renal failure and provides an opportunity to test different compounds or extracts which could have renoprotective properties [20]. Although both sexes of rats were used in this study, there was no apparent difference between males and females in the measured parameters.

\section{Biochemical changes}

Serum creatinine and BUN are commonly used to assess glomeruli filtration rate as well as concentrating and diluting capacity of tubular functions of the kidneys. An increase in values of these markers may indicate development and extent of renal tubular damage [21]. Increased BUN may be associated with kidney disease or failure/blockade of the urinary tract by a kidney stone, congestive heart failure, dehydration or bleeding in the digestive tract [22].

In the present study, administration of khat at a high dose $(400 \mathrm{mg} / \mathrm{kg})$ had significantly increased serum creatinine and BUN levels, suggesting that khat use may impair renal function by reducing the ability of kidneys to handle these products. These effects perhaps may originate from changes in the renal blood flow and glomerular filtration rate induced by khat treatment [23].

Al- Motarreb and Broadley [24] reported that khat chewers experience an increase in heart rate and body temperature as well as sweating and cold extremities, which dictate the presence of peripheral vasoconstriction. On the bladder, khat chewing produced a fall in urinary flow rate, an effect that has been shown to be inhibited by the selective $\alpha_{1}$-adrenoceptor antagonist, indoramine, and therefore attributed to activation of this receptor subtype [25]. Peripheral vasoconstriction 


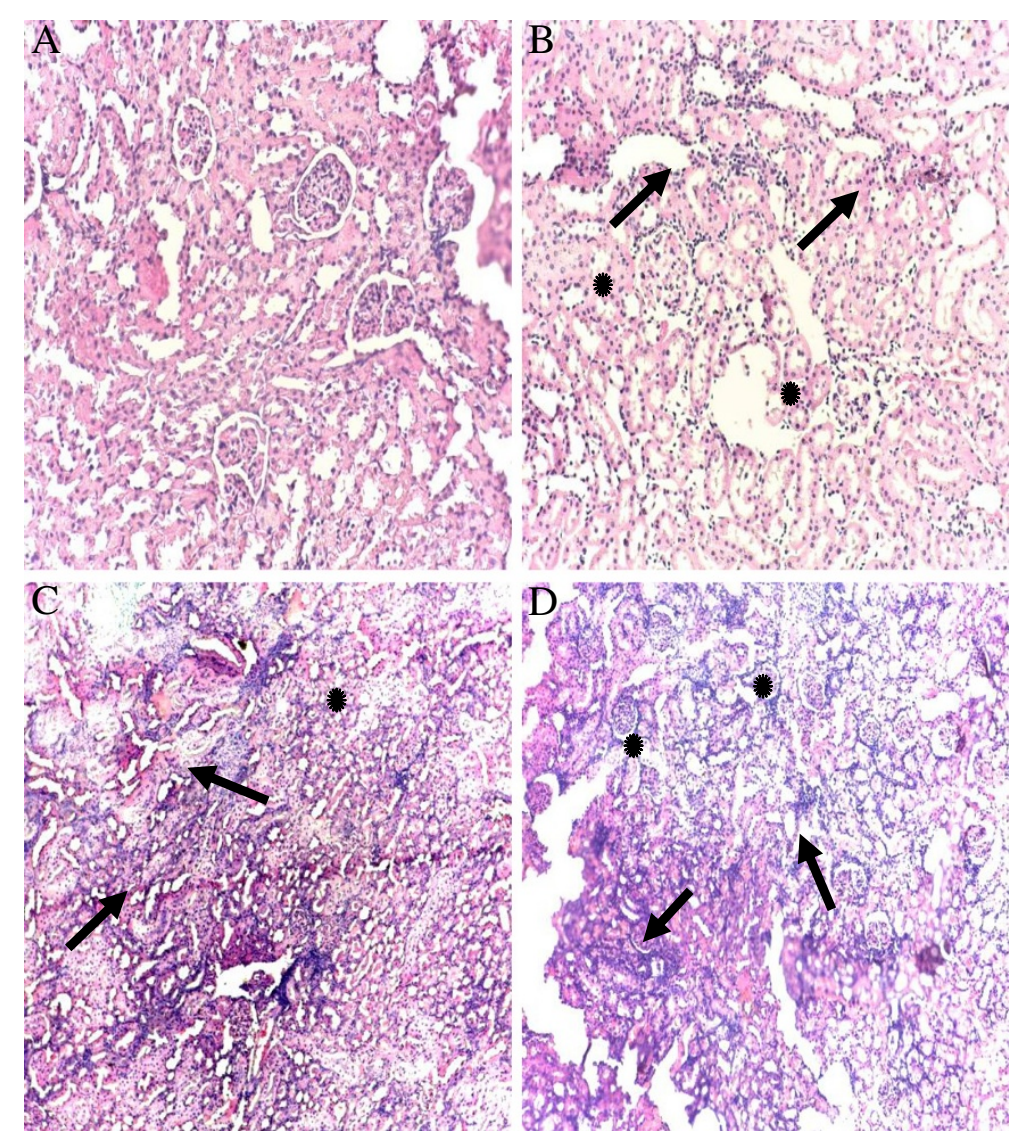

Figure 1 Photomicrographs of hematoxilin and eiosin stained renal tissues for khat and/or gentamicin treated rats: The kidneys of the control rats (treated with Tween80) showed normal renal parenchyma with normal histo-architecture (A). On the other hand K400 rats showed mild to moderate interstitial inflammation (arrows), hypertrophied glomerular capillaries and injured dilated Bowman's capsule $\left(^{*}\right)(B)$. GEN rats showed marked infiltrative inflammatory cells and vascular congestion (arrows) and vacuolar degeneration of the tubules (*) (C). Furthermore, GK400 rats revealed more extensive and marked infiltrative inflammation, complete destruction of glomerular capillaries (arrows), degeneration of the tubules and Foamy appearance in the tubular epithelial cells $\left(^{*}\right)$ (D). Magnification $\times 40$. K400, khat $400 \mathrm{mg} / \mathrm{kg}, \mathrm{GEN}$, gentamicin $100 \mathrm{mg} / \mathrm{kg}$, GK400, khat 400 mg/kg + gentamicin 100 mg/kg.

following khat administration as described above would explain the raised serum creatinine and BUN levels. Compared to khat, gentamicin treatment resulted in a marked elevation of both creatinine and BUN levels. Thus, it is plausible to assume that alteration of these renal indices caused by khat treatment is relatively mild to moderate compared to gentamicin. The fact that the same dose of khat produced significant alteration compared to gentamicin when given along the renotoxic drug reinforces the notion that high dose of khat per se has a direct renotoxic potential.

SOD and catalase are the predominant, if not exclusive, defenses against free radicals in which SOD catalyze the dismutation of superoxide radicals to hydrogen peroxide that in turn is removed by catalase or glutathione peroxidase [26]. In agreement with previous observations [27], the present study also indicated gentamicin-induced oxidative stress, as shown by a significant decrease in kidney catalase and SOD activities. Exhaustion of enzymatic renal oxidative defense mechanisms along with enhanced reactive oxygen species generation could result in oxidative damage in gentamicin treated rats [28]. K400 significantly decreased the activity of both renal SOD and catalase enzymes, suggesting that the extract is able to generate free radicals or directly inhibit the action of these antioxidant enzymes. This finding is concordant with recent studies in which administration of khat extract or its alkaloid fractions were shown to alter activities of the free-radical metabolizing/scavenging enzyme system $[6,29]$.

The peroxidation of lipids gives rise to a number of secondary products, MDA being the principal and most studied one. This aldehyde is a highly toxic molecule and has been considered as more than just a marker of lipid peroxidation [30]. The rationale for MDA as a biomarker relies on the fact that it is solely derived from lipid peroxides and changes in MDA concentration reflects changes in lipid oxidation level [31]. Baliga et al. [32] documented that gentamicin caused lipid peroxidation in the kidney via 
reactive oxygen species generation. The results in the present study clearly indicated that oral administration of khat at doses of $200 \mathrm{mg} / \mathrm{kg}$ and $400 \mathrm{mg} / \mathrm{kg}$ had shown accelerated lipid peroxidation in the renal tissues as reflected by an increase in MDA levels, possibly by inducing generation of reactive oxygen species. Indeed, Al-Hashem et al. [29] reported that the toxic effect of khat extract on hepatic and renal functions might be related to lipid peroxidation as indicated by a significant increase in lipid peroxidation biomarkers.

It is, however, worth noting that whilst gentamicin induced elevation of renal MDA levels were accentuated by K400 co-treatment, no apparent change was observed with concomitant administration of K200 and GEN. Moreover, K200 did not reduce antioxidant enzymes to a significant level, though it elevated the MDA levels significantly. This could possibly point to the fact that khat should be able to decrease antioxidant defense mechanisms as well as enhance lipid peroxidation in order to produce significant nephrotoxic effect. This effect appears to be a function of dose, where moderate doses produce lipid peroxidation, probably via increase in free radical production, but high doses are associated with both peroxidation and abrogation of the enzymatic defense mechanism.

Khat is known to contain several constituents, including alkaloids and flavonoids. The flavonoid fraction has been demonstrated to have no effect on antioxidant enzymes activity $[6,9]$, which could probably implicate the alkaloids or other constituents for the observed effect. However, it is widely accepted that antioxidant substances may potentially have deleterious effects (pro-oxidation action), particularly when precise modulation of ROS levels are necessary for normal cell function. The fact that antioxidants may exhibit pro-oxidant activity depending on dosage and presence of free transition metals at cellular sites [33-35], and appearance of the toxicity with higher dose does not totally exclude the contribution of flavonoids.

\section{Morphologic pathology}

K200 and K400 rats showed a significant body weight loss compared to controls, although the extent of loss was lower than gentamicin. Gentamicin-induced weight loss could be associated with direct renal tubular injury. Injury of the renal tubules leads to subsequent loss of tubular cells that take part in renal water reabsorption. This is accompanied by loss of water, leading to dehydration and loss of body weight [36]. On the other hand, increased catabolism associated with gentamicin-induced acute renal failure causes acidosis. Acidosis results in anorexia that in turn decreases oral food intake, eventually culminating in body weight loss [37]. Khat-associated reduction in body weight could therefore be attributed to kidney damage, as it was shown to cause mild-tomoderate injury in the histopathologic evaluation, but it could also be ascribed to khat-induced delay in intestinal absorption that contributes to some degree of malnutrition [38-40] or increased plasma leptin level that leads to loss of appetite [41]. Kidney weight gain probably explained by the edema that was caused by gentamicin and khat induced acute tubular necrosis [19].

The histopathological results were paralleled by serum, antioxidant and lipid peroxidation findings. Rats treated with gentamicin revealed extensive and marked renal tubular necrosis. Although khat alone was not able to produce extensive kidney damage, it resulted in a wideranging damage that even included the epithelial cells when combined with gentamicin. This histopathological evidence once again clearly reaffirms the direct nephrotoxic potential of khat. Although the mechanism by which khat produces nephrotoxicity is not clearly known, it is thought to result from local decrease in blood supply, possibly from narrowing of the renal arteries $[24,42]$.

\section{Conclusions}

Administration of khat at higher dose $(400 \mathrm{mg} / \mathrm{kg})$ was shown to cause renal damage. Moreover, gentamicininduced disturbance in renal indices were considerably accentuated by high dose of crude khat extract. Khat, alone or with gentamicin was also found to alter renal histopathology, normalized kidney weight and body weight of rats. Thus, the data collectively indicate that khat does not play a permissive role but has a direct nephrotoxic potential, albeit to a small extent, that creates synergism when combined with other nephrotoxic agents such as gentamicin.

The use of khat at higher dose may cause oxidative stress by depleting anti-oxidative mechanisms or by enhancing pro-oxidant components of tissues, leading to renal injury. More reasonably, khat seems to be able to perturb the delicate balance between protective and damaging mechanisms of a cell that is required for optimal activity, thereby producing oxidative damage.

Competing interests

The authors declare that they have no competing interest.

\section{Authors' contributions}

All authors involved in the design and write up of the study, and ZS conducted the actual study and the statistical analysis. Both authors approved the submitted version of the manuscript.

Acknowledgement

The authors are thankful to Addis Ababa University for the financial support

Received: 1 October 2013 Accepted: 18 February 2014

Published: 20 February 2014

\section{References}

1. Patel NB: Mechanism of action of cathinone: the active ingredient of khat (Catha edulis). East Afr Med J 2000, 77:329-332. 
2. Cox G, Rampes R: Adverse effects of khat: a review. Adv Psychiatric Treat 2003, 9:456-463.

3. Belew M, Kassaye M, Enquselassie F: The magnitude of khat use and its association with health, nutrition and socio-economic status. Eth Med J 2000, 38:11-26.

4. Gebissa E: Scourge of life or an economic lifeline? Public discourses on khat (Catha edulis) in Ethiopia. Subst Use Misuse 2008, 43:784-802.

5. Al-MotarrebA A-HM, Broadley KJ: Khat chewing, cardiovascular diseases and other internal medical problems: the current situation and directions for future research. J Ethnopharmacol 2010, 113:432-442.

6. Al-Qirim TM, Shahwan M, Zaidi KR, Uddin Q, Banu N: Effect of khat, its constituents and restraint stress on free radical metabolism of rats. J Ethnopharmacol 2002, 83:245-50.

7. Al-Habori M, Al-Aghbari A, Al-Mamary M, Baker M: Toxicological evaluation of Catha edulis leaves: a long term feeding experiment in animals. J Ethnopharmacol 2002, 83:209-217.

8. Al-Mamary M, Al-Habori M, Al-Aghbari A, Baker M: Investigation into the toxicological effects of Catha edulis leaves: a short term study in animals. Phytother Res 2002, 16:127-132.

9. Al-Zubairi A, Al-Habori M, Al-Geiry A: Effect of Catha edulis (Khat) chewing on plasma lipid peroxidation. J Ethnopharmacol 2003, 87:3-9.

10. Alsalahi A, Abdulla MA, Al-Mamary M, Noordin MI, Abdelwahab IA, Alabsi AM, Shwter A, Mohammed A, Alshawsh MA: Toxicological features of catha edulis (khat) on livers and kidneys of male and female sprague-dawley rats: a subchronic study. J Evid Based Complementary Altern Med 2012. doi: 10.1155/ 2012/829401.

11. Institute for Laboratory Animal Research (ILAR): , Guide for the Care and Use of Laboratory AnimalsWashington, D.C: National Academy Press; 1996.

12. Connor JD, Rostom A, Makonnen E: Comparison of the effects of khat extracts and amphetamine on motor behaviors in mice. J Ethnopharmacol 2002, 81:65-71.

13. Bedada W, Engidawork E: The neuropsychopharmacological effects of Catha edulis in mice offspring born to mothers exposed during pregnancy and lactation. Phytother Res 2010, 24:268-276.

14. Abdulwaheb M, Makonnen E, Debella A, Abebe D: Effect of Catha edulis Forsk (khat) extracts on male rat sexual behavior. J Ethnopharmacol 2007, 110:250-256.

15. Admassie E, Engidawork E: Subchronic administration of Catha edulis F. (khat) extract is marked by elevation of cardiac biomarkers and subendocardial necrosis besides blood pressure alteration in rats. J Ethnopharmacol 2011, 136:246-253.

16. Mohammed A, Engidawork E: Reproductive parameters are differentially altered following subchronic administration of Catha edulis F. (Khat) extract and cathinone in male rats. J Ethnopharmacol 2011, 134:977-983.

17. Parlakpinar $\mathrm{H}$, Tasdemir S, Polat A, Bay-Karabulut A, Vardi N, Ucarn M: Protective effect of chelerythrine on gentamicin-induced nephrotoxicity. Cell Biochem Funct 2006, 24:41-48.

18. Annie S, Rajagopala PL, Malinib S: Effect of Cassia auriculata Linn. Root extract on cisplatin and gentamicin-induced renal injury. Phytomedicine 2005, 12:555-560.

19. Erdem A, Gundogn NU, Usubutun A, Kilic K, Erdem SR, Kara A: The protective effect of taurin against gentamicin nephorotoxicity. Nephrol Dial Transplant 2000, 15:1175-1182.

20. Ali BH: Gentamicin nephrotoxicity in humans and animals: some recent research. Gen Pharmacol 1995, 26:1477-1487.

21. Kakadiya J, Shah N: Renal function markers: a short review. J Innov Trends Pharm Sci 2010, 1:270-273.

22. Gowda S, Desai PB, Kulkarni SS, Hull W, Math AK, Bernekar SN: Markers of renal function tests. N Am J Med Sci 2010, 2:170-173.

23. Kalix $P$, Braenden O: Pharmacological aspects of the chewing of khat leaves. Pharmacol Rev 1985, 37:149-164.

24. Al-Motarreb A, Broadley KJ: Coronary and aortic vasoconstriction by cathinone, the active constituent of khat. Auton Autacoid Pharmacol 2003, 23:319-326.

25. Nasher AA, Qirbi AA, Ghafoor MA, Catterall A, Thompson A, Ramsay JW, Murray-Lyon IM: Khat chewing and bladder neck dysfunction. A randomized control trial of -adrenergic blockade. Br J Urol 1995, 75:597-598.

26. Maritim AC, Sanders RA, Watkins JB: Diabetes, oxidative stress, and antioxidant: a review. J Biochem Mol Toxicol App Pharmacol 2003, 223:86-98.
27. Karadeniz A, Yildirim A, Simsek N, Kalkan Y, Celebi F: Spirulina plantensis protects against gentamicin-induced nephrotoxicity in rats. Phytother Res 2008, 22:1506-1510.

28. Karahan I, Atessahin A, Yilmaz S, Ceribas AO, Sakin F: Protective effect of lycopene on gentamicin-induced oxidative stress and nephrotoxicity in rats. Toxicology 2005, 215:198-204.

29. Al-Hashem FH, Bin-Jaliah I, Dallak MA, Nwoye LO, Al-Khateeb M, Sakr HF: Khat (Catha edulis) extract increases oxidative stress parameters and impairs renal and hepatic functions in rats. Bahrain Med Bull 2011, 33:1-9.

30. Rio DD, Stewart AJ, Pellegrini N: A review of recent studies on malondialdehyde as toxic molecule and biological marker of oxidative stress. Nutr Met Cardiovasc Dis 2005, 15:316-328.

31. Lykkesfeldt J: Malondialdehyde as biomarker of oxidative damage to lipids caused by smoking. Clin Chim Acta 2007, 380:50-58.

32. Baliga R, Ueda N, Walker PD, Shah SV: Oxidant mechanisms in toxic acute renal failure. Drug Metab Rev 1999, 31:971-997.

33. Baradaran A, Nasri H, Rafieian-Kopaei M: Comment on: anti-oxidative stress activity of stachyslavandulifolia aqueous extract in humans. Cell J 2013, 15:272-273.

34. Rafieian-Kopaei M, Baradaran A, Rafieianet M: Oxidative stress and the paradoxical effects of antioxidants. J Res Med Sci 2013, 18:628.

35. Rafieian-Kopaei M: Medicinal plants and the human needs. J Herb Med Plarmacol 2012, 1:1-2.

36. Ali BH, Al-Qarawi AA, Haroun EM, Mousa HM: The effect of treatment with gum Arabic on gentamicin nephrotoxicity in rats: a preliminary study. Renal Failure 2005, 25:15-20.

37. Ali BH, Abdel Gayoum A, Bashir AA: Genatamicin nephrotoxicity in rats: some biochemical correlates. Pharmacol Toxicol 1992, 70:419-423.

38. Gunaid AA, El-Khally FM, Hassan NA, Murray-Lyon IM: Chewing qat leaves slows the whole gut transit time. Saudi Med J 1999, 20:444-447.

39. Heymann TD, Bhupulan A, Zureikat NE, Drinkwater C, Giles P, Murray-Lyon IM: Khat chewing delays gastric emptying of a semi-solid meal. Alimentary Pharmacol Ther 1995, 9:81-83.

40. Makonnen $\mathrm{E}$ : Constipating and spasmolytic effects of khat (Catha edulis Forsk) in experimental animals. Phytomedicine 2000, 74:309-312.

41. Al-Dubai W, Al-Habori M, Al-Geirly A: Human khat (Catha edulis) chewers have elevated plasma leptin and nonesterified fatty acids. Nutr Res 2006 26:632-636

42. Conger J: Hemodynamic factors in acute renal failure. Adv Renal Replace Ther 1997, 4:25-37.

\section{doi:10.1186/1472-6882-14-66}

Cite this article as: Shewamene and Engidawork: Subacute administration of crude khat (Catha edulis F.) extract induces mild to moderate nephrotoxicity in rats. BMC Complementary and Alternative Medicine 2014 14:66.

\section{Submit your next manuscript to BioMed Central and take full advantage of:}

- Convenient online submission

- Thorough peer review

- No space constraints or color figure charges

- Immediate publication on acceptance

- Inclusion in PubMed, CAS, Scopus and Google Scholar

- Research which is freely available for redistribution 